\title{
When Visuals Are Boundary Objects in System Dynamics Work
}

\section{Author: Laura J. Black}

This is the peer reviewed version of the following article: [Black, Laura J. "When Visuals Are Boundary Objects in System Dynamics Work." System Dynamics Review 29, no. 2 (April 2013):

70-86. doi:10.1002/sdr.1496.], which has been published in final form at http:// dx.doi.org/10.1002/sdr.1496. This article may be used for non-commercial purposes in accordance with Wiley Terms and Conditions for Self-Archiving.

Black, Laura J. "When Visuals Are Boundary Objects in System Dynamics Work." System Dynamics Review 29, no. 2 (April 2013): 70-86. doi:10.1002/sdr.1496.

Made available through Montana State University's ScholarWorks scholarworks.montana.edu 


\title{
When visuals are boundary objects in system dynamics work ${ }^{\dagger}$
}

\author{
Laura J. Black ${ }^{\mathrm{a}, \mathrm{b} *}$
}

\begin{abstract}
Using modeling representations as boundary objects provides an important aid to collective meaning-making. By understanding the construct of boundary objects, which arises from sociological studies of cross-boundary work, we can increase our effectiveness in using visual representations to facilitate shared understanding for joint action. This paper draws on theories of social construction, distributed cognition, and boundary objects to build the argument that visual representations provide the crucial pivot between the system dynamics modeling method and socially constructing shared meaning. I highlight the role of visuals particularly in the context of group model building because it provides an explicit occasion devoted to shared meaning-making through facilitated execution of the system dynamics method. Many system dynamicists use the model-building process and simulation analyses to socially construct shared understanding among people with differing domain expertise, and the theoretical principles and practical guidelines described here can usefully inform efforts beyond participatory modeling workshops. Copyright @ 2013 System Dynamics Society
\end{abstract}

The problem-based starting point of the system dynamics method places the approach squarely in action-oriented territory. We want to understand how a problem arises endogenously because we want to address it or reduce its undesirable consequences. In any setting in which we desire joint action (Blumer, 1969), constructing shared meaning of the problem and solution context among multiple stakeholders must be a critical part of the process. Those seeking to share understanding of relations and explore points of leverage through simulations may be a modeler and her client, modelers with differing domain expertise, or modelers working with non-modelers who bring different perspectives to the problem. While participatory modeling merits an explicit focus in this paper, the theoretical principles and practical guidelines described here can usefully inform practices beyond group modeling settings (e.g. Andersen et al., 2012; Kim and Andersen, 2012).

\section{Adding science to the craft of group model building}

Group model building has been a rich aspect of system dynamics practice and research for more than 25 years. Because it interactively involves stakeholders in multiple phases of

\footnotetext{
${ }^{a}$ Montana State University, Bozeman, MT 59717-3040, U.S.A.

${ }^{\mathrm{b}}$ Greer Black Company, Bozeman, MT 59772-3607, U.S.A.

* Correspondence to: Laura J. Black, Montana State University, PO Box 173040, Bozeman, MT 59717-3040, U.S.A. E-mail: lblack@montana.edu

${ }^{\dagger}$ Accepted by Luis Luna-Reyes Received 13 January 2013; Revised 30 May 2013; Accepted 10 June 2013
}

Copyright @ 2013 System Dynamics Society 
the problem-identification and problem-solving processes, it is a socio-technical approach to solving socio-technical problems. The practice is particularly desirable when addressing "messy problems" (Ackoff, 1979; Vennix, 1999; Vennix et al., 1996), "wicked problems" (Rittel and Webber, 1973; Vennix, 1996), or "tangled" problems (Dawes et al., 2009). Costanza and Ruth (1998, p. 184) have argued that involving multiple stakeholders in creating "simplified, high generality models" helps establish consensus on problem scope and on appropriateness of assumptions that later proves crucial to taking actions based on subsequent model analyses. As pressing ecological, energy, and health issues (e.g. Hirsch et al., 2012; Hovmand et al., 2012; Stjernquist et al., 2012; Otto and Struben, 2004) draw more diverse stakeholders into conversations for policy formation and resource use, group modeling becomes as an increasingly important practice among system dynamicists.

Group model-building scholarship has focused largely on how to do it, and how to do it better. Vennix's comprehensive guide on facilitating learning through group model building (1996) provides direction on facilitating group conversations as well as on translating the customary steps in system dynamics model construction and analysis to the context of group decision making. Other research takes the form of best-practice reports on roles of modeling/facilitation team members (Richardson and Andersen, 1995), scripts for executing small sub-processes that produce interim workshop deliverables (Andersen and Richardson, 1997; Hovmand et al., 2011), and the need for effective improvisation (Richardson and Andersen, 2010). Additional research centers on outcomes of group model building (Rouwette et al., 2002; Vennix et al., 1996) and notes that the process does not consistently lead to collective actionable insights about systemic solutions.

Missing from this scholarship is a theory-rich basis for informing us why certain practices work and under what conditions the same practices could fail to yield effective outcomes. Calls to add "more science to the craft" (Andersen et al., 1997) invite us to understand more deeply the social and intellectual processes unfolding in the rich interactive medium of a group model-building session. Visser (2007) proposed that principles from communication theory can ensure more consistently productive outcomes for facilitators of participatory building. In a similar vein, this paper offers "more science" by applying the theoretical construct of boundary objects to the setting of group model building through the practicebased theory of distributed cognition. Boundary objects are tangible representations-such as text, a diagram, or a formal process — of dependencies across disciplinary, organizational, social, or cultural lines (Star and Griesemer, 1989). I propose that, when the visual representations used in group model building can function as boundary objects, the outcomes of group model building improve.

Theoretically based insights supplement our on-the-ground experiences and keen intuitions with principles applicable to many specific situations. Put another way, absent a theory-rich understanding, we are limited to and by best practices-partially reported results of trial-and-error experimentations. If we can explain why a best practice works, then we become more powerful not only in activities related to the best practice but also in activities unaddressed by best practices. We can become more flexible, consistently wielding expertise across inconsistent situations.

The sections that follow first describe social complexities inherent to messy, wicked, or tangled problems and then explain the role of visual representations in cognition. Next I provide a brief overview of key sociological studies developing the construct of boundary objects and interpret some examples of model building and simulating processes as 
viewed through the boundary-object lens. The paper concludes by highlighting practical guidelines for using visuals as boundary objects and posing some themes for further theoretical development.

\section{Why some problems are messier than others}

To view group model-building practices through the sociological construct of boundary objects, it makes sense first to focus on the participatory modeling setting in terms of social processes, rather than model construction. People often turn to group model building if they cannot even agree on "the problem," or when a situation is so complex that they cannot find an entry point from which to identify possible solutions.

"Wicked" (Rittel and Webber, 1973) and "messy" (Ackoff, 1979; Vennix, 1999) problems are characterized as situations in which social and technical aspects are so intertwined that it is impossible to address the technical issues without engaging the social dynamics, and vice versa. Like a Rubik's cube, these problems have interlocking constraints on goals, resources, activities, and outputs, so that when we try to engage or improve one aspect of the situation, we limit or destroy what we have to work with in other aspects. To make matters more complex, goals and priorities may change over time, and resources for addressing the problem may also change before the problem is well understood, much less "solved" (Conklin, 2006; Rittel and Webber, 1973). Some scholars argue that people cannot even comprehend a wicked problem deeply until they have tried and failed to implement a solution (Conklin, 2006). Alternatively, "tangled" problems are those whose challenges arise from the need to share information and knowledge across multiple organizational jurisdictions or disciplinary practices, rather than from the problem's nature itself (Dawes et al., 2009). In these problems, under-defined or non-routine social interactions that cut across customary work boundaries introduce the complexity that renders otherwise routine problems unmanageable.

Both interdependency among technical elements of the problem and intertwining social aspects of the problem or stakeholders make wicked and tangled problems challenging. Understanding dense technical interdependencies is sufficiently tough to merit a rigorous method such as system dynamics. But when different resources or activities comprising the problem reside under the influence of different individuals or groups, then understanding the interdependencies becomes an inherently social as well as an intellectual process. When many people must navigate complex relationships among interconnected resources, goals, and constraints, technically correct data and expertise are simply insufficient to accomplish the task. Therefore, the process of framing and developing solutions to messy problems must be fundamentally social.

Why we need socially constructed agreements (or, why can't everyone just see I'm right?)

Socially constructing agreements among people holding different values, objectives, methods, tools, and understandings is more than negotiation. Early theories of social construction (Berger and Luckmann, 1966) asserted that we interact with the world around us as if it were objectively defined-but we arrive at "objective" meanings only through 
accumulating social interactions that refine and reinforce meanings that we assign our perceptions. As we engage with others, we speak about these meanings as if they are facts, and so "inter-subjectively" shape the world we share. Our "world" is unproblematic as long as nothing disturbs our routines. Anything that disrupts our ability to interact socially as we have before, from large-scale disasters to personal injuries or seemingly unsolvable problems, can cause us to re-examine the meanings we view as facts. Disruptions can bring us to a point of recognizing that, while we share a common world with those around us, we may not share common framings of what is important, common perceptions of appropriate actions, or common sense about what to do next (Berger and Luckmann, 1966).

This characterizes well the situations that motivate group model building. Wicked and tangled problems offer a class of routine-disrupting situations. Stakeholders in the resources and consequences of these problems may hold such differing views that they cannot agree on "the problem" or may not share the vocabulary to describe it; if they agree on how to describe it, they may not see eye to eye on how, or where, or when, to intervene. In such a situation skilled facilitators and experts in designing and executing group processes prove valuable. Offering more than conversation management, group model building addresses the intertwined aspects of interdependent elements and social aspects of the problem by using the system dynamics method in a structured, facilitated group setting. Because the traditional system dynamics method (Forrester, 1961; Sterman, 2000) is largely silent on how to manage socially constructing agreements among many individuals, group model-building practices and research have evolved as a way to engage simultaneously the interdependent technical and social dimensions of wicked, messy problems.

Specifically, the link between the traditional system dynamics method and the facilitation in group model building rests on the visual representations generated by the method -behavior-over-time graphs, causal loops, stock-flow diagrams, and simulations-which become shared in the group setting. System dynamics representations that portray explicitly causal relations and mutual influence (as depicted in feedback loops) among variables lead people to recognize they can be "right," and yet have a partial view of the situation that is more insightfully viewed in a larger context. The structured facilitation that develops these representations through stakeholders' discussions constructively manages the problem's social aspects. Group model building may streamline technical complexity through aggregations of incidents into patterns and accumulating variables and with a formal grammar of stocks, flows, and information links. But it does not reduce social complexity through hierarchies or formal organizational structures; rather it demarcates social complexity's relevance by focusing conversations on the social constraints and opportunities as they relate to each part of the visually represented causal structure and dynamics.

\section{The role of framing in socially constructing agreements}

In complex situations with ambiguous cues and causality and high-stakes outcomes, strategies for identifying and solving problems emerge from contests among "framings" that coherently describe the most salient dimensions of the context and their relations in ways to motivate actions and particular outcomes (Kaplan, 2008). Benford and Snow's (2000) review

of framing as related to social movements describes framing as an active, dynamic process of constructing meaning in a contentious context. Noonan (2007) explains that the "framing" 
we use in approaching a situation relates to what we see as salient in that context; a frame contains our focus on how we view ourselves, how we view the other, and how we view the task at hand. The frame construct is especially appropriate to discussing a joint-action approach to wicked problems, because frames are inherently action-oriented and result from emergent meaning-making (Benford and Snow, 2000).

Benford and Snow (2000) identify three common core framing tasks: diagnostic (understanding the problem), prognostic (proposing a solution), and motivational (prompting people to act on a proposed solution). I assert that executing the system dynamics process in a group setting facilitates each of these core framing tasks. By starting with the presenting problem in terms of behavior-over-time and moving to describe interacting causal relationships that can generate the problematic behavior, it explicitly creates a shared diagnostic framing. It advances a shared prognostic view by using both mental and electronic simulations as ways to speculate on-and observe possible consequences of-measures taken to remediate the problem. And it promotes shared motivational framing because participants can see where their own points of leverage, their own abilities to act, lie in the interrelated context of problem-and-solution relationships. Further, the system dynamics modeling and simulation process can help stakeholders manage their own and others' expectations of time frames for achieving desired results, which can also create a shared motivational perspective.

Studies of framing have also identified features of framings that vary across different occasions, including the direction or locus of attribution (e.g. exogenous or endogenous causes); flexibility versus rigidity of interpretation; inclusivity versus exclusivity of stakeholders; scope of interpretation; and degree of resonance (Benford and Snow, 2000). Group model building can become a powerful process in socially constructing shared views because it employs visual representations to assist in creating flexible, inclusive frames (multiple stakeholders participate in the problem and the solution) with broad interpretive scopes that resonate with participants because of their own roles in creating and naming the modeling-oriented abstractions. The system dynamics approach to understanding endogenous sources of patterns, over time, graphically shows how one person's output is another's input, and how one participant's achieved goal is another's evolving problem. Visuals associated with shared meaning-making in the system dynamics process therefore remove weight from purely political rhetorics or issue-selling approaches to framing. They enlarge the stakeholders' view (perhaps literally) of endogenously generated behaviors rooted in tangible and intangible accumulations that participants agree are influential on the problem at hand, and a shared mental model (Kim, 2009) of the situation may emerge. Before we can appreciate the distinctive role of visuals in creating shared framings, however, we must consider that cognition is not all in our heads, but relies significantly on what we see as we think.

\section{We think with what we see: Points of leverage for social construction}

System dynamicists may take for granted the behavior-over-time graphs, causal-link and causal-loop diagrams, stock-flow maps, and simulation outputs in graphs and tables that shape essential elements of the method for problem identification and problem solving

with a "system" approach. The box-and-arrow diagrams first presented in Industrial Dynamics (Forrester, 1961) offered a box icon to represent an integration equation, 
visually underscoring that an integration accumulates its net flow over time. Causal loops, which do not distinguish between accumulations and other variables such as flows or parameters, were later used as a lower-complexity tool to engage non-modelers in describing causal relations, with an emphasis on recognizing when a change in a variable led through feedback to a reinforcing or negating change in that same variable later in time. (For a discussion of diagramming conventions in system dynamics that provides both historical and critical perspectives, see Lane, 2000.) When shared, these familiar visual representations pose a powerful and possibly undervalued point of leverage for advancing meaning-making conversations among modelers and non-modelers alike. To understand the significant role that shared visual representations can play in shaping shared understanding, I draw on the work of Lave (1988), whose studies examined physical and location-specific aspects of cognition.

\section{Cognition distributed}

Through extensive ethnographic studies, Lave (1988) analyzed how adults addressed mathematical challenges in different settings. She discovered that people with demonstrated algebraic prowess as indicated by performance on math tests did not use algebraic approaches to do math problems in other settings, but that people "thought math" using the tools they had at hand in the moment. They conceptualized a problem as one of numerical abstractions if a calculator or spreadsheet program or other tool lending itself to numerical representation was nearby. But in the kitchen, when confronted with a measurement challenge such as preparing a lunch that includes two-thirds of the day's allotment of three-quarters of a cup of an ingredient, one subject she studied, who was well educated in higher mathematics, represented the problem to himself by measuring out three-quarters of a cup of the ingredient, placing that amount on a cutting board, separating it into three equal parts, and returning one part to the container (Lave, 1988). Lave's study culminated in the theory that cognition is grounded in the practices we use when exercising our competence-that is, in whatever tools are at hand to represent the problem and our reasoning-in-process to ourselves.

This view of cognition distributed between our minds and "out there" gives special import to visual representations of problems and relations in the group model-building setting (Black and Andersen, 2012). Reference modes, causal-link diagrams, and stockand-flow sketches offer participants opportunities to represent the familiar problem in unfamiliar ways. These different representations help participants think of, or "re-cognize," aspects of the problem in different ways. A logical implication of Lave's theory of distributed

cognition is that changing the visual representation of a problem can change how we think about it, and how we can think about it.

When differing points of view inhibit shared understanding of a messy problem, negotiating a coherent representation of it through facilitated discussion (Zagonel, 2002) can help participants begin to share thoughts in substantive ways, unlike talk that meanders without a representation to anchor it. Because system dynamics visual representations especially focus on relations among aspects of problems, showing dependencies among accumulations and the flows that create, sustain, and deplete them, or how one aspect of the problem influences another, diagrams can depict mutual influence and interdependence. The customary visual representations of system dynamics 
created in the group model-building setting therefore offer substantive, socially shared experiences and approaches to recognize and change individuals' thinking - to redistribute their cognition, so to speak-about interdependent aspects of the problem. If these representations are to offer traction on intractable problems, however, they must be used in certain ways; they must function as "boundary objects" for participants (Black and Andersen, 2012).

\section{The sociological construct of "boundary objects"}

A boundary object, most simply, is a representation-perhaps a diagram, sketch, sparse text, or prototype-that helps individuals collaborate effectively across some boundary, often a difference in knowledge, training, or objective. A formal theoretical description of boundary objects was developed through a grounded theory approach (Glaser and Strauss, 1967) undertaken by Star and Griesemer (1989). In a seminal paper describing how amateur specimen collectors, professional biologists, and museum administrators worked together to create well-documented research zoological archives from rather amorphous collections donated by people with more enthusiasm than education, the authors observed that some objects seemed "adaptable" because people with different kinds of knowledge or objectives could interpret them in different ways. While retaining a coherent identity across domains, these boundary objects helped advance conversations when the participants had "partial jurisdiction over the resources represented by th[e] object" (Star and Griesemer, 1989, p. 412) and when their differing expertise or objectives led them to make interpretive claims that were mismatched, in conflict, or overlapping.

In studies of product development work requiring multiple kinds of expertise, Henderson (1991) elaborated on the concept of boundary objects, emphasizing the ways in which artifacts-representations, tools, and technologies-shape knowledge coordination. She observed that working sketches of products under development could elicit voluntary, innovative new ideas or, alternatively, "conscript" participants to specific approaches to the work-in-process. Carlile $(1997,2002)$, whose early work examined the objects used to represent dependencies and (mis-)communicate work across multiple organizational departments during product development, articulated a general form (Glaser and Strauss, 1967) of the theoretical construct. He distilled three aspects of the artifacts that function as robust boundary objects: they are "concrete"; they represent dependencies among actors; and they are transformable by all actors, meaning that anyone involved can change the representation to show more clearly consequences of the dependencies portrayed by the artifact.

\section{Boundary objects in group model building}

Applying the sociological perspective of boundary objects to group model-building practices reveals system dynamics representations as relatively concrete pictures of interdependence that evolve and are transformed by participants' facilitated discussions. The system dynamics approach to problem articulation and cause-and-effect hypotheses offer abundant examples of representations that can function as boundary objects. To ground this notion in our shared experiences, I discuss below several aspects of model 
building or simulation in groups, moving from more general descriptions to specific reported practices, as seen through the lens of boundary objects.

\section{Problems articulated as behavior-over-time charts}

The traditional approach to system dynamics modeling begins with identifying a problem statement (Morecroft and Sterman, 1994; Sterman, 2000), often portrayed in words as well as graphically in a reference mode (Sterman, 2000) or behavior-over-time graph (Wolstenholme, 1994) or time-path chart (Warren, 2003). In the group setting, these representations already become potential boundary objects, as they offer participants stepping stones to agreement on facets of the messy problem, even if they do not agree on which aspect is most important. Inviting participants to summarize "the problem" invites them to use their own language to describe their challenges, and the terms participants use become the real-world variable names (Forrester, 1961; Sterman, 2000), grounding the model-to-be in vocabulary they customarily use to express their competence. In boundary object terms, a problem statement or reference mode, drawn on a board or paper visible to all members of the group, serves as an initial concrete representation of the issue that brings participants together. Because they can all see it, it becomes part of their shared experience, while remaining interpretively adaptable to participants' respective realms of responsibility. Because it is an external representation, it shifts focus from individuals as sources of the problem to a depersonalized shared-problem representation. Keeping visible early problem representations throughout the modelbuilding sessions offers a concrete "re-presentation" of why participants desire to talk to each other. Throughout group model-building work, a facilitator can use visual representations constructed in earlier activities as concrete reminders of previous agreements (framings) among participants and so advance the discussion from (a series of) shared points of view.

\section{Causal-loop diagrams and stock-flow sketches of cause-effect hypotheses}

Similarly, causal-loop diagrams and stock-flow sketches of stakeholders' assertions of causes and effects among problem elements provide rich examples of visual representations functioning as boundary objects. Drawn by the facilitator/modeler, these diagrams externalize problem understanding, reducing social tensions that often accompany problematic dependencies. Again, because variables are called by participants' own terms, rather than mathematical terms, the diagrams are concretely related to their world. By their very nature, these diagrams show information link arrows and accumulations and flows indicating causal dependencies among problem elements. Because effective facilitators add to and modify these diagrams as discussions continue, stakeholders observe that their participation transforms the emerging shared understanding of the problem.

\section{The "concept model" script}

Andersen and Richardson (1997), in their articulation of small pieces of group process they call "scripts" (also see Hovmand et al., 2011, for elaborations of scripts), discuss the 
challenge of expecting to move as close as possible to creating simulating models during facilitated conversations, when participants may have little or no experience with simulation or even with systemic views of their situation. To address this, the authors present "a very stripped-down 'concept' model during the first 20 minutes or so of a modeling conference, both to engage participants in the problem and to describe to them what a simulation model is" (Andersen and Richardson, 1997, p. 117). The concept model's overt purpose is to familiarize participants with stock, flow, and link representations, possibly to introduce how these representations relate to algebraic relations, and to demonstrate the connections between represented structure (the constellation of stocks, flows, and information links) and behavior over time as portrayed in the structure's simulation graphs (see also Richardson, 2012).

Because of these [simplicity] constraints and the sharply defined pedagogical purposes of these concept models, they are typically rather bad first cuts at system dynamics models.... Yet they must lead the group in the direction of robust and appropriate formulations for the problem at hand (Andersen and Richardson 1997, p. 117).

In light of the transformable characteristic of robust boundary objects, we can see that concept models help participants engage in appropriate representations and formulations of problem aspects, not despite the concept model's being "rather bad," but because the concept model clearly shows something about the problem and also clearly needs participants' input to become more accurate and useful. As Richardson says, because they are tiny and algebraically obvious or simple, "these models are wronger than most" (2012, p. 47); they therefore invite the participants to transform them. Concept models are deliberately "impoverished replicas" (Lonergan, 1957) of the real system, focused on the dependencies between dynamic behaviors and system structures, and designed for transformative iteration.

\section{Simulation forums}

Making simulating models transformable can be especially challenging. By their nature, simulating models can become "high-tech, low touch" to many stakeholders because they invoke multiple mathematical abstractions and functions. Frequently participants lack expertise to directly manipulate models or link variable behaviors to feedback loops (Zagonel, 2002). Stave's $(2002,2003)$ reports of using public forums to explore a system dynamics model of water usage in Las Vegas, Nevada, however, provide insights into how a simulating model can serve as a boundary object. While she did not conduct a conventional group model-building exchange, her use of groups is similar in that the public forum focus was to socially construct shared awareness of water-supply shortages and to advance public education on effects of water usage and of wateruse-reduction efforts (Stave, 2003). She invited 83 community participants, from teachers and environmental professionals to students and retirees, to propose policies for prolonging the time at which demand for water exceeds supply. Working in groups, participants identified policies that were then simulated and explored, and the model output was used to move forward conversations about possible policies for water use and water conservation. 
In these $2^{1 / 2}$-hour workshops, the model helped elucidate counterintuitive causes and effects (for instance, that reducing outdoor use conserved water supplies significantly more than reducing indoor use by the same amounts), which participants could relate to their own experiences and observations, often revising their perceptions and biases during the process. The visual model representations and simulated outputs "shifted the discussion from who was to blame for the water problem ... and how to solve it ... to how the system works and why it responds to policy changes as it does” (Stave, 2003, p. 311). Stave further noted:

Because we introduced the problem graphically (explaining that the goal was to move the crossing point [of water demand and water supply] further out into the future) and presented the model output in the same form, participants could judge easily whether their suggestion had the desired effect and how it compared to other suggestions. At first, participants focused on the crossing point, but then began to notice that different options had different effects on the supply and demand lines. They began asking questions about what caused the lines to change (p. 311).

Stave's model representation visually portrayed dependencies among problem aspects that participants could connect to their own respective realms of influence. It served as a boundary object for participants' understanding, not only because it showed dependencies and consequences of those dependencies, but also because, by inviting participants to create the policies that were simulated, she began to move the model and its output from "the expert's domain" into a domain that participants could influence and transform.

These examples illustrate how visual representations can serve as boundary objects as long as they are wielded in ways that preserve their transformability by the participants. Additionally, it is useful to address explicitly another boundary in the participatory modeling context that visual representations must span: the boundary of methodological expertise between the facilitator/modeler team and the non-modeler participants.

\section{Boundary objects and power: Crossing yet another boundary}

While it is not their explicit purpose to do so, boundary objects redistribute power among the participants using them. In the group model-building setting, we can consider two kinds of power addressed. First, structured facilitation ensures that the ranking person in the room (the president, director, or manager, of others present) does not dominate the conversation. Participants placing their trust in the facilitator/modeler team effectively grant permission for the facilitator to redistribute, during the group model-building sessions, customary power relationships that exist (Black and Andersen, 2012). Second, we must acknowledge that the facilitator/modeler team wields enormous power over participants through the process of choosing what to represent in the shared visuals. Richardson and Andersen (2010) have noted "the person who holds the pen holds the power," describing a tension between mirroring what participants say and selecting carefully what to represent visually. Describing improvisation as a critical element of group model building, they assert that representations from affinity models to causal diagrams and stock-flow maps can serve as boundary objects with three uses-remembering, facilitating, and modeling-to help manage tensions inhering in group modeling. These 
tensions lie not simply among participants' differing points of view, but also between "client mental models and system dynamics modeling principles; between natural language and model equations" (Richardson and Andersen, 2010, p. 23). "LERT" is the acronym offered for Listen, Edit, Report, and Transform, as these activities form two distinct, and contradictory, functions. Listen-and-Report focuses on faithfully recording the participants' "exact words, concepts, and phrases," while Edit-with-Transformations requires finding ways to "filter" participants' thoughts and phrasings and structure them in ways that lend them more easily to modeling (Richardson and Andersen, 2010, pp. 26-27).

Seeing the activity as "filtering" and "editing” participants' understandings may suggest, however, that participants' input is not valued. Alternatively, through the boundary object lens, we can view shared visual representations that emerge during group modeling as collaborative representations that incorporate both the modeler's expertise and the participants' rich experiences-that is, as objects crossing the modeler-participant boundary as well as spanning participant-participant boundaries.

\section{Practical implications for system dynamicists}

Practically, we note a fourth characteristic necessary for visual representations to work as boundary objects: iterate-ability. We must be able to iterate with visual representations frequently and easily if they are to remain transformable. Of course, this has implications for the cost and speed with which visual representations can be created and changed. If a visual representation requires significant time or money to create, then iterating on it becomes less likely. A long text document, for example, is not easily absorbed or quickly altered to reflect or incorporate an alternative point of view. A model that is cumbersome to modify hinders iteration and therefore may restrict transformability.

For this reason, microworlds that focus on changing individuals' understanding usually do not function as boundary objects, since the representations may or may not represent the microworld user's perspective, are often un-transformable by him or her, and do not necessarily construct shared understanding (there is no guarantee that the user actually internalizes the modeler's insights or other users' learning). Boundary objects are visual representations that synchronously span a boundary of expertise or objectives among multiple individuals. Figure 1 provides a perspective of conditions under which some commonly used system dynamics representations may function as boundary objects. It also indicates that simulations, models, and diagrams can be used as "bludgeoning tools" rather than boundary objects (Black and Andersen, 2012), when they are used to communicate unidirectionally, silencing others' voices rather than inviting stakeholders to transform the representations, even when multiple people having expertise in multiple domains are present.

I emphasize practical implications because, as Kurt Lewin said, "there is nothing so practical as a good theory" (1951). Below are guidelines for using visual representations as boundary objects in contexts of creating shared understanding:

- Keep representations of the problem visible-particularly early representations such as problem statements and reference modes-to remind participants why they want to talk to each other. Such a visual signifies a previous agreement among stakeholders of the complex problem that requires a shared diagnostic framing if progress is to be made. 


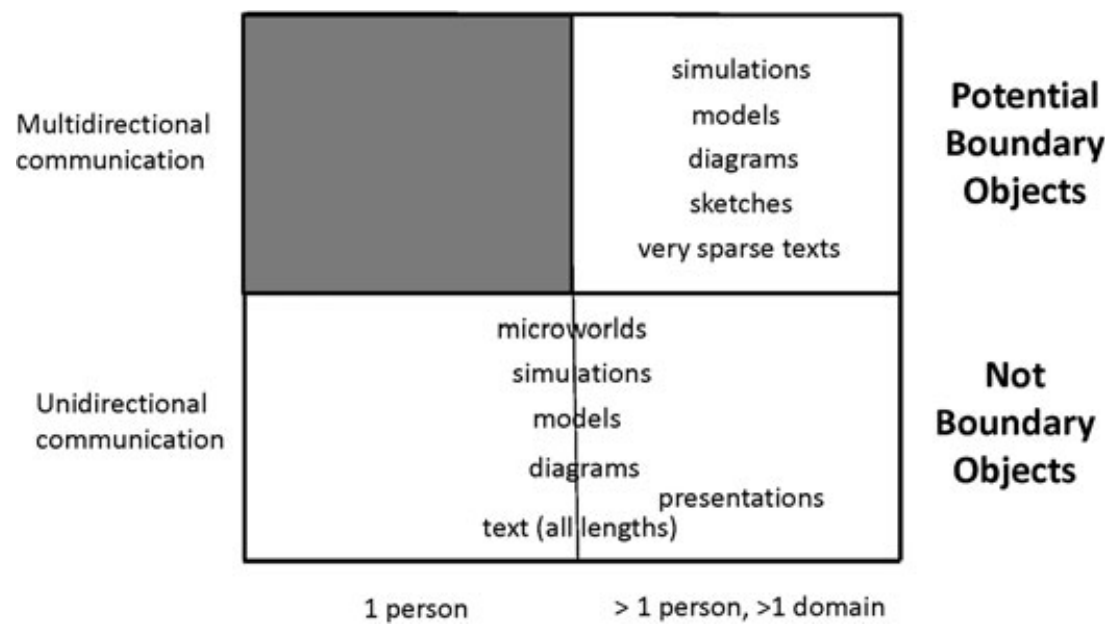

Fig. 1. Boundary objects are visual representations that synchronously span a boundary of expertise or objectives among multiple individuals.

Note: Some might argue that a representation can function as a boundary object for a single individual over time, since the individual is no longer exactly the same person he was (perhaps having acquired knowledge from a new domain or undertaken different or additional objectives) as at an earlier time when he created or last viewed the representation.

- Use work-in-process visual representations not only to remind participants of previous agreements but also to advance the discussion. When the conversation mires in ways that suggest traditional conflicts across traditional boundaries, direct and re-direct attention to the visual representations (thereby depersonalizing the discussion) and ask what needs to be changed so that the picture better reflects the issue at hand.

- Make sure representations visually portray dependencies among aspects of the problem as they relate to participants' ability to influence or experience the consequences of the situation. This assists in making the visuals concrete relative to participants' capacity to act (Mead, 1934), as well as underscoring interlocking constraints and resources.

- Provoke participation by showing "bad" visual works-in-process that invite people to share what they know and transform the representations at hand. While it may be uncommon to advocate sharing incomplete and incorrect work, this often motivates participants to express their own perspectives. Conversely, showing work that appears neat and complete often shuts down conversation because stakeholders infer that "it's too late" to provide differing views or untidy nuances.

- Increase the transparency and transformability of models by inviting participants to develop scenarios that can be simulated. Linking scenario elements explicitly to variables in the model, and creating time and space for participants to identify for themselves links between the simulated behaviors and the model's structure, can significantly advance achievement of the shared prognostic and motivational framing tasks.

\section{Theoretical implications: Advancing substantive theories}

Representations are not necessarily boundary objects in and of themselves. Any particular representation, depending how it is used by actors, can serve as a boundary object, inviting 
conversations that transform understanding as they also transform the representation in use. Any representation can also be used as a "conscription device" (Henderson, 1991) or bludgeoning tool, closing down conversation as it enlists compliance to a single way of looking at the problem (Black and Andersen, 2012). It may not always be obvious in the moment what exactly curtails participation. The construct's key attributes of concreteness, representation of dependencies, and transformability are all situated attributes, located not in representations themselves, but between visuals and the expertise present. Substantive theories exploring these situated attributes in group contexts can offer further insights into why some group modeling projects result in successful joint action while others do not.

For example, math equations are not concrete to many people participating in group model building. Without elaborated explanations and "telling the story," models can appear opaque and un-understandable (not concrete) to participants. Certainly, plain language and using participants' terms as variable names help make representations concrete; but can we characterize more specifically to what extent "concreteness" is related to participants' engaging in activities of writing, drawing, and hearing their own voices discuss problem aspects in small groups? To what extent might concreteness be influenced, for example, by whether participants hand-draw their own diagrams, watch diagrams emerge hand-drawn on a whiteboard, or observe diagrams appear icon-by-icon on a computer screen?

What aspects of group interaction, in addition to constructing causal hypotheses and feedback loops, can constructively portray critical dependencies among stakeholders? Future research that undertakes to video-record participatory modeling sessions and then systematically review and code participants' speech and gestures for acknowledgement and agreement of dependencies among their domains can substantively inform our understanding of what constitutes "a dependency" among participants and the ways that a dependency may manifest in social relations, technical processes, and shared visual representations. Innovative data-collection tools such as devices that record communication patterns including proximity of speakers, interruptions and accelerations of speech, and consistency of posture (e.g. Sociometric Solutions, 2012) could yield more information with which to construct theoretical views of how and under what conditions cross-boundary interactions unfold.

An abiding challenge remains: How can we collectively deepen our understanding of ways to engage participants in formulating model relationships and in designing and analyzing simulations to deepen shared understanding of dependencies and the opportunities for joint action that feedback loops often represent? The failure modes of transformability are many; the most conspicuous is when the facilitator does not represent someone's input or inadvertently listens to and represents one participant's view to the exclusion of others' (Black and Andersen, 2012). But there are other ways to make a representation non-transformable. When a diagram becomes so complicated that it appears intractable, it can become inaccessible to participants and therefore un-transformable by them. What theory-building, either deduced from recent neuroscience research on cognition and learning, or induced from and grounded in rich observations of interactions over representations, can help us discern conditions under which a representation evolves beyond participants' perceived capacity to act?

At a higher level of abstraction, we can undertake identifying which scripts dominate in establishing shared diagnostic, prognostic, or motivational framings. Planning participatory modeling efforts with scripts related to each framing type can ensure that we navigate gracefully through all aspects of framing critical to initiating joint action successfully. Further, we would then have a broader basis for understanding when the facilitator/modeler needs to return to or revisit certain kinds of scripts if, for example, there is a rupture in 
group process, the addition of new participants midstream, or the loss of a critical participant or member of the facilitator/modeler team mid-project.

Stretching farther afield, can we use an understanding of boundary objects in system dynamics work to advance participatory interactions in constructing other forms of simulation such as agent-based modeling? What relatively concrete representations could allow stakeholders to transform ad hoc the assumptions embedded in modeled agents and link the complex outcomes of simulated interactions to the simplified behavioral rules of the individuals represented? Alternatively, what can boundary objects help us understand about the usefulness of social simulation games and the opportunities and limitations they hold? To what extent, or under what conditions, for example, could an avatar-based interface lead to shared understanding for joint action in microworld simulations?

While preliminary and perhaps ill formed, these exploratory questions point to rich potential for advancing our collective theoretical understanding of why certain modeling practices work well to construct shared meanings. In this way, we can provide more refined points of leverage for engaging socially complex problems with hopes for intelligent and effective joint action.

\section{Conclusion}

In this paper I call attention to visual representations as a crucial link between the system dynamics method and group facilitation in the social construction processes of participatory modeling. By wielding knowledgeably the construct of boundary objects, we can understand why certain practices are especially effective in shaping shared understanding. This study therefore offers one step by which substantive theories of group model building-and more generally, shared meaning-making-can advance.

This work stands in a line of scholarship that links system dynamics methods and practices with the philosophies, principles, and theories of broader social science communities (e.g. Grossler, 2007; Lane, 2001a, 2001b; Luna-Reyes et al., 2006). Placing system dynamics in the context of other veins of social science helps scholars who do not use system dynamics recognize method elements that can be useful to them. Also, it allows system dynamicists to see the field with a more expansive social science perspective, draw on powerful theories to improve practices, and build bridges to scholars in other research areas for mutually beneficial collaborations.

\section{Acknowledgements}

The author thanks Don Greer, Navid Ghaffarzadegan, Hyunjung Kim, and Eliot Rich for thoughtful comments on an earlier draft of this paper, Peter Hovmand for insightful conversations on participatory modeling, and two anonymous reviewers and the editors, who made constructive suggestions.

\section{Biographies}

Laura Black is Associate Professor in the College of Business at Montana State University and a principal in Greer Black Company. Her research and consulting interests center on collaborative practices for innovating across disciplines, organizations, and community sectors. 


\section{References}

Ackoff RL. 1979. The future of operational research is past. Journal of the Operational Research Society 30(2): 93-104.

Andersen DF, Richardson GP. 1997. Scripts for group model building. System Dynamics Review 13(2): 107-129.

Andersen DF, Richardson GP, Vennix JAM. 1997. Group model building: adding more science to the craft. System Dynamics Review 13(2): 187-201.

Andersen DL, Luna-Reyes LF, Diker VG, Black LJ, Rich E, Andersen DF. 2012. The disconfirmatory interview as a strategy for the assessment of system dynamics models. System Dynamics Review 28(3): 255-275.

Benford RD, Snow DA. 2000. Framing processes and social movements: an overview and assessment. Annual Review of Sociology 26: 611-639.

Berger PL, Luckmann T. 1966. The Social Construction of Reality: A Treatise in the Sociology of Knowledge. Doubleday: Garden City, NY.

Black LJ, Andersen DF. 2012. Using visual representations as boundary objects to resolve conflict in collaborative model-building approaches. Systems Research and Behavioral Science 29(2): 194-208.

Blumer H. 1969. Symbolic Interactionism: Perspective and Method. University of California Press: Berkeley, CA.

Carlile PR. 1997. Understanding knowledge transformation in product development: making knowledge manifest through boundary objects. PhD thesis, University of Michigan, Ann Arbor, MI.

Carlile PR. 2002. A pragmatic view of knowledge and boundaries: boundary objects in new product development. Organization Science 13(4): 442-455.

Conklin EJ. 2006. Dialogue Mapping: Building Shared Understanding of Wicked Problems. Wiley: Chichester.

Costanza R, Ruth M. 1998. Using dynamic modeling to scope environmental problems and build consensus. Environmental Management 22(2): 183-205.

Dawes SS, Cresswell AM, Pardo TA. 2009. From "need to know" to "need to share": tangled problems, information boundaries, and the building of public sector knowledge networks. Public Administration Review 69(3): 392-402.

Forrester JW. 1961. Industrial Dynamics. Systems Dynamics Series. Productivity Press: Portland, OR.

Glaser BG, Strauss AL. 1967. The Discovery of Grounded Theory: Strategies for Qualitative Research. Aldine: Chicago, IL.

Grossler A. 2007. System dynamics projects that failed to make an impact. System Dynamics Review 23(4): 437-455.

Henderson K. 1991. Flexible sketches and inflexible data bases: visual communication, conscription devices, and boundary objects in design engineering. Science, Technology, and Human Values 16(4): 448-473.

Hirsch G, Homer J, Milstein B, Sterman J, Ingersol C, Scherrer L, Landy L, Fisher E. 2012. ReThink health dynamics: understanding and influencing local health system change. In Proceedings of the 2012 International System Dynamics Conference, St Gallen, Switzerland. System Dynamics Society.

Hovmand P, Rouwette E, Andersen D, Richardson G, Calhoun A, Rux K, Hower T. 2011. Scriptapedia: a handbook of scripts for developing structured group model building sessions. Proceedings of the 2011 International System Dynamics Conference, Washington, D.C. System Dynamics Society.

Hovmand P, Nelson A, Carson K. 2012. Understanding social determinants from the ground up. In Proceedings of the 2012 International System Dynamics Conference, St Gallen, Switzerland. System Dynamics Society.

Kaplan S. 2008. Framing contests: strategy making under uncertainty. Organization Science 19(5): 729-752.

Kim H. 2009. In search of a mental model-like concept for group-level modeling. System Dynamics Review 25(3): 207-223. 
Kim H, Andersen DF. 2012. Building confidence in causal maps generated from purposive text data: mapping transcripts of the Federal Reserve. System Dynamics Review 28(4): 17.

Lane DC. 2000. Diagramming conventions in system dynamics. Journal of the Operational Research Society 51(2): 214-218.

Lane DC. 2001a. Rerum Cognoscere Causas Part I: How do the ideas of system dynamics relate to traditional social theories and the volunteerism/determinism debate? System Dynamics Review 17(2): 97-118.

Lane DC. 2001b. Rerum Cognoscere Causas Part II: Opportunities generated by the agency / structure debate and suggestions for clarifying the social theoretic position of system dynamics. System Dynamics Review 17(4): 293-309.

Lave J. 1988. Cognition in Practice: Mind, Mathematics, and Culture in Everyday Life. Cambridge University Press: Cambridge, UK.

Lewin K. 1951. Field Theory in Social Science: Selected Theoretical Papers. Harper \& Row: New York.

Lonergan B. 1957. Insight: A Study of Human Understanding. Longmans, Green: London.

Luna-Reyes LF, Martinez-Moyano IJ, Pardo TA, Cresswell AM, Andersen DF, Richardson GP. 2006. Anatomy of a group model-building intervention: building dynamic theory from case study research. System Dynamics Review 22(4): 291-320.

Mead GH. 1934. Mind, Self, and Society: From the Standpoint of a Social Behaviorist. The University of Chicago Press: Chicago.

Morecroft JDW, Sterman JD (eds). 1994. Modeling for Learning Organizations. Productivity Press: Portland, OR.

Noonan WR. 2007. Discussing the Undiscussable: A Guide to Overcoming Defensive Routines in the Workplace. Wiley: San Francisco, CA.

Otto P, Struben J. 2004. Gloucester Fishery: lessons from a group modeling intervention. System Dynamics Review 20(4): 287-312.

Richardson GP. 2012. Concept models in group model building. System Dynamics Review 29(1): 42-55.

Richardson GP, Andersen DF. 1995. Teamwork in group model building. System Dynamics Review 11(2): 113-137.

Richardson GP, Andersen DF. 2010. Improvised facilitation: a third leg on the group model building stool. In Proceedings of the 2010 International System Dynamics Society Conference. Seoul, South Korea. System Dynamics Society.

Rittel HWJ, Webber MM. 1973. Dilemmas in a general theory of planning. Policy Sciences 4(2): 155-169.

Rouwette E, Vennix JAM, Van Mullekom T. 2002. Group model building effectiveness: a review of assessment studies. System Dynamics Review 18(1): 5-45.

Sociometric Solutions. 2012. Sociometric Badge 03-02 Preliminary User Guide. http://www. sociometricsolutions.com [12 May 2013].

Star SL, Griesemer JR. 1989. Institutional ecology, "translations” and boundary objects: amateurs and professionals in Berkeley's Museum of Vertebrate Zoology, 1907-39. Social Studies of Science 19(3): 387-420.

Stave KA. 2002. Using system dynamics to improve public participation in environmental decisions. System Dynamics Review 18(2): 139-167.

Stave K. 2003. A system dynamics model to facilitate public understanding of water management options in Las Vegas, Nevada. Journal of Environmental Management 67(4): 303-313.

Sterman JD. 2000. Business Dynamics: Systems Thinking and Modeling for a Complex World. Irwin McGraw-Hill: Boston, MA.

Stjernquist I, Sverdrup H, Schlyter P, Belyazid S, Koca D, Jonsson-Belyazid U. 2012. Searching for the magnificent mountain landscape: environmental management in the Swedish mountain areas. In Proceedings of the 2012 International System Dynamics Conference, St Gallen, Switzerland. System Dynamics Society.

Vennix JAM. 1996. Group Model Building: Facilitating Team Learning Using System Dynamics. Wiley: New York. 
Vennix JAM. 1999. Group model-building: tackling messy problems. System Dynamics Review 15(4): 379-401.

Vennix JAM, Akkermans HA, Rouwette E. 1996. Group model-building to facilitate organizational change: an exploratory study. System Dynamics Review 12(1): 39-58.

Visser M. 2007. System dynamics and group facilitation: contributions from communication theory. System Dynamics Review 23(4): 453-473.

Warren K. 2003. The Critical Path: Building Strategic Performance Through Time. Vola Press: London.

Wolstenholme E. 1994. A systematic approach to model creation. In Modeling for Learning Organizations, Morecroft JDW, Sterman JD (eds). Productivity Press: Portland, OR.

Zagonel A. 2002. Model conceptualization in group model-building: a review of the literature exploring the tension between representing reality and negotiating a social order. In Proceedings of the 2002 International System Dynamics Conference, Palermo, Italy. System Dynamics Society. 